\title{
A BusCa da EXPERIÊNCIA EM SUa Fonte: Matéria, Movimento e Percepçáo em Bergson
}

\author{
Silene Torres Marques
}

\begin{abstract}
RESUMO: Nosso objetivo é destacar algumas questóes concernentes ao problema da matéria e do movimento na filosofia de Bergson. Questôes presentes em seu segundo livro, Matéria e memória, as quais indicam uma nova orientação de sua filosofia: a passagem da psicologia à metafísica; mais precisamente, a introdução do tema do movimento e da duração "fora de nós". O primeiro capítulo do livro, ao caracterizar o universo material como um conjunto de imagens, desempenha um papel fundamental nessa passagem, a qual efetivamente se dá no quarto capítulo, momento em que elabora uma metafísica da matéria. Para além desse contexto, é na direção de seu terceiro livro, $A$ evolução criadora, que essa metafísica da matéria consequentemente aponta.
\end{abstract}

PALAVRAS-CHAVE: Bergson. Matéria. Movimento. Percepção. Duração.

1. O Ensaio sobre os dados imediatos da consciência (1889) inaugura a filosofia de Bergson, trazendo à luz reflexôes marcantes sobre o tempo interior. Tendo como origem a crítica à noção de tempo da física e, sobretudo, a constatação de que esse tempo não dura, tais reflexôes introduzem a noção de duração, assim definida: "A duração totalmente pura é a forma que adquire a sucessão de nossos estados de consciência quando nosso eu se deixa viver, quando ele se abstém de estabelecer uma separação entre os estados presentes e os estados anteriores" (BERGSON, 1970, p. 67). Essa duraçáo é, portanto, a duração da consciência, sucessão contínua, movimento indivisível de estados heterogêneos e dinâmicos que, ao mesmo tempo, se sucedem e se conservam: cada estado anuncia o estado seguinte e contém em si o estado que o precedeu, sendo, por conseguinte, como ressalta o texto tardio de $O$ pensamento e o movente, "[...] prolongamento ininterrupto do passado num presente que penetra o futuro" (BERGSON, 1970, p. 1273).

\footnotetext{
${ }^{1}$ Departamento de Filosofia - UFSCar.
} 
Ora, se há um esforço argumentativo em todo o livro (principalmente nos capítulos 2 e 3), para mostrar que esse movimento é apreendido pela consciência imediata como absoluto, isto é, como liberdade, Bergson, no entanto, não alude ao movimento ou à duração que se daria fora da consciência, no mundo material ou na totalidade do universo. Restringindo-se à experiência psicológica do movimento, afirma "em si desconhecido" o movimento enquanto um fenômeno exterior (BERGSON, 1970, p. 82). À questão sobre a duração "fora de nós" responde referindo-se a uma incompreensível razão em virtude da qual os "[...] fenômenos parecem suceder-se, e não desenvolverem-se todos ao mesmo tempo" (BERGSON, 1970, p. 137). Num outro ponto, argumenta que não é necessário "[...] dizer que as coisas exteriores duram, mas antes que há nelas qualquer inexprimível razão em virtude da qual não poderemos considerá-las em momentos sucessivos de nossa duração sem constatar que elas mudaram" (BERGSON, 1970, p. 148). Ou seja, considerado um "fato de consciência”, o movimento investigado no Ensaio é tấo somente o movimento (a duração) experimentado pela consciência.

O segundo livro de Bergson, todavia, introduz uma configuração diferente às suas investigaçóes: amplia o domínio da experiência para além dos limites da consciência interna, possibilitando o tratamento do movimento no âmbito da realidade exterior. Gilles Deleuze resume muito bem esse momento:

É apenas na medida em que o movimento for compreendido como pertencendo às coisas tanto quanto à consciência que ele cessará de confundir-se com a duraçáo psicológica, que ele deslocará dela o ponto de aplicação, e por isto, tornará necessária uma participação direta das coisas na própria duração. Se há qualidades nas coisas não menos que na consciência, se há um movimento das qualidades fora de mim, é necessário que as coisas durem à sua maneira. É necessário que a duração psicológica não seja senão um caso bem determinado, uma abertura sobre uma duração ontológica. É necessário que a ontologia seja possível. (DELEUZE, 1997, p. 43-44).

Matéria e memória torna possível a ontologia. Mais precisamente, torna possível uma metafísica da matéria. Após definir a matéria como a totalidade do campo de imagens, no primeiro capítulo, Bergson estende ao mundo material, no quarto capítulo, determinadas conclusóes do Ensaio, antes válidas para a consciência: refere-se ao "princípio geral" de um "método" já utilizado em seu primeiro livro, que, aplicado ao "problema da matéria”, conduz a resultados reveladores do "movimento real"; por fim investiga, a partir da experiência do movimento, a realidade metafísica da matéria. Vale ressaltar o que pontua, 
no prefácio: "Nosso primeiro capítulo define essa maneira de olhar a matéria; nosso quarto capítulo dela tira as consequências" (BERGSON, 1970, p. 163). Nesse sentido, pretendemos então mostrar o que está em jogo nesses dois capítulos extremos do livro e como essas "consequências" implicam uma redefinição da matéria que tem por fundamento a análise direta do movimento e das qualidades sensíveis "fora de nós".

2. Tudo começa no prefácio do livro, quando nosso filósofo define os termos a partir dos quais o dualismo será considerado: "Este livro afirma a realidade do espírito, a realidade da matéria, e procura determinar a relação entre eles a partir de um exemplo preciso, o da memória. Portanto, é claramente dualista" (BERGSON, 1970, p. 161). Porém, ressalta o filósofo, é preciso suplantar certas "dificuldades teóricas" que o dualismo clássico sempre levantou, dificuldades relativas à "concepção ora realista, ora idealista, que se faz da matéria”. Tais concepçôes são excessivas e, para ultrapassá-las, é preciso pensar a matéria como imagem. A matéria é "um conjunto de "imagens" e isto significa que ela é uma "existência situada a meio caminho" entre "aquilo que o idealista chama uma representação", e "aquilo que o realista chama uma coisa" (BERGSON, 1970, p. 161). Bergson acredita que essa sua concepção da matéria o coloca no ponto de vista do senso comum, pois, contra o idealista, o senso comum se recusaria a acreditar que o objeto existe apenas em seu espírito; para ele, o objeto existiria independentemente de sua consciência. Por outro lado, contra o realista, ele também se recusaria a acreditar que não percebemos o objeto tal como ele é nele mesmo; a cor que o olho atribui ao objeto e a resistência que a mão encontra nele estão no objeto, "[...] são os elementos constitutivos de uma existência independente da nossa" (BERGSON, 1970, p. 161). Assim, para o senso comum o objeto possui uma existência independentemente da nossa, existe em si mesmo, mas por outro lado ele é “em si mesmo pitoresco tal como o percebemos" (BERGSON, 1970, p. 162).

Descartes e Berkeley aparecem aqui como interlocutores de Bergson: ora, se ao confundir a matéria com a extensão geométrica Descartes a colocava "muito longe de nós", não era preciso, para reaproximá-la, fazê-la coincidir com nosso próprio espírito (BERGSON, 1970, p. 162). Ao considerar a extensão desprovida de suas qualidades segundas, Descartes faz da substância uma realidade que escapa à percepção e ao mesmo tempo elabora uma cisão entre ela e seu atributo essencial (DESCARTES, 1979, p. 77-95). Por outro lado, Berkeley reabilita as qualidades segundas como constitutivas, o que é 
enunciado na expressão esse est percipi. Mas, ao determinar a realidade do que denomina "ideias", traduz "ser percebido" por "ideia". Dessa maneira, a realidade também escapa à percepção e o espírito acaba tornando-se condição do aparecer. É preciso, logo, “[...] deixar a matéria a meio caminho entre o ponto para onde a impelia Descartes, e aquele para onde a puxava Berkeley" (BERGSON, 1970, p. 163). Assim sendo, como imagem ela não pode ser considerada cópia ou quadro das coisas, pois existe no mundo, no entanto, de outra parte, como vamos ver, ela é tal como a percebemos, pois náo lhe acrescentamos nada: antes, suprimimos parte de suas relaçóes com as outras imagens (BERGSON, 1970, p. 185-186).

Ora, se tais são as características da imagem, como então pensar o estatuto da consciência e da representação? Ou, mais simplesmente, como se dá nossa relação perceptiva com esse mundo das imagens? Vejamos inicialmente como Bergson encaminha a investigação desse capítulo inovador que abre o livro, o qual tem como título: "Da seleçẫo das imagens para a representação. O papel do corpo".

Suspendendo todas as teorias da matéria e do espírito, as discussóes sobre a idealidade ou realidade do mundo exterior, Bergson inicia o capítulo apresentando o mundo material, conjunto de imagens, como uma plenitude de movimentos:

Eis-me, portanto, na presença de imagens [...], imagens percebidas quando abro meus sentidos, não percebidas quando os fecho. Todas essas imagens agem e reagem umas sobre as outras em todas as suas partes elementares... (BERGSON, 1970, p. 169).

Apesar dessa descrição inicial, Bergson não explora a especificidade do movimento material. Seu propósito é fazer teoria do conhecimento, isto é, repensar a relação entre matéria e percepção da matéria, e sua análise inovadora acentua o papel do corpo, imagem que, fazendo parte desse conjunto, dele se destaca. Partindo do campo neutro das imagens, logo define o lugar privilegiado que essa imagem, o corpo vivo, aí ocupa: sendo uma imagem, recebe e devolve movimento, mas é antes de tudo um centro de ação: "[...] parece escolher, numa certa medida, a maneira de devolver o que ele recebe" (BERGSON, 1970, p. 171)2. Como um condutor, recolhe e transmite movimentos, "[...] quando não os retém a certos mecanismos motores, determinados se a ação

\footnotetext{
2 "A posição privilegiada do corpo vivo lhe confere um poder real: se há uma ampliaçáo de seu horizonte perceptivo, as imagens lhe são indiferentes; se este horizonte se contrai, as imagens se ordenam "distintamente" de acordo com suas 'facilidades' de toque e locomoção, reenviando-lhe, como um espelho, sua influência eventual, isto é, refletindo sua ação possível sobre elas" (BERGSON, 1970, p. 172).
} 
é reflexa, escolhidos se a ação é voluntária”, e, por tudo isso, é essencialmente um centro de indeterminação: corpo é vida, vida que se diferencia das imagens “[...] devido à complexidade e à variabilidade de suas reaçôes” (BERGSON, 1970, p. 223). Desse modo, mesmo se aplicando a um único nível de realidade, aquele designado pelo termo imagem, Bergson "[...] não se contenta com uma identidade de natureza entre o corpo e a matéria" (WORMS, 2004, p. 121). A vida introduz a diferença. Ora, como essa diferença se expressa, no nível da percepçáo? O que está em jogo, como frisamos, é a dedução da percepção da matéria a partir do corpo vivo, centro de ação indeterminada, e suas necessidades vitais ${ }^{3}$. Façamos uma breve consideração sobre essa dedução.

Contestando mais uma vez os realistas e os idealistas no que diz respeito ao postulado de que a "consciência natural" mantém com o mundo uma "relação de atividade cognitiva", um "interesse inteiramente especulativo", recusando tal postulado ${ }^{4}$ em nome justamente da busca de uma clareza na compreensão do "triplo problema da matéria, da consciência e da relação entre elas" (BERGSON, 1970, p. 179), Bergson insiste primeiramente no caráter pragmático e não especulativo da percepção; atividade acima de tudo indeterminada, índice de uma relação que é adaptação do ser vivo ao mundo que o circunda. Perceber não significa conhecer, contemplar: é acima de tudo agir. O exame da estrutura do sistema nervoso comprova essa postura teórica: a comparação entre a estrutura do cérebro e a da medula espinhal mostra que há apenas uma diferença de complexidade ou de complicação, e não de natureza, entre as funçôes do cérebro e a atividade reflexa da medula. Num organismo rudimentar, a percepção de um objeto com o qual entra em contato se reduz basicamente à irritabilidade e à contratilidade, suas reaçôes sendo mecânicas e resultando em movimentos automáticos. No vertebrado superior, o cérebro recolhe o movimento, o analisa e seleciona os movimentos ou respostas às excitaçôes recebidas do exterior; sua função é, portanto, mediadora. Bergson refere-se ao grande número de vias motoras que podem abrir-se, "todas conjuntamente" no cérebro como "resposta" a um mesmo estímulo vindo da periferia: o cérebro podendo "conduzir o movimento recolhido a um órgão de reação escolhido" ou "abrir a este movimento a totalidade de vias motoras" para que ele esboce suas reaçóes possíveis (BERGSON, 1970, p. 181). Ora, quanto mais se desenvolve, mais numerosos e afastados são os pontos do

\footnotetext{
${ }^{3}$ Haja vista que Bergson pretende contestar a tese (sustentada por realistas e idealistas) de que o cérebro ou os movimentos cerebrais determinam ou criam a representação do mundo material.

${ }^{4}$ Que justamente traz implícita a perspectiva de que representaçóes nasceriam ou estariam contidas no cérebro.
} 
espaço dispostos pelo sistema nervoso para relacionar-se com os mecanismos motores cada vez mais complexos, aumentando assim a latitude da ação. Nesse sentido, é possível constatar uma lei rigorosa que une a extensão da percepção e a intensidade da ação do ser vivo, a qual permite verificar que uma maior indeterminaçâo se vincula a uma maior "esfera de consciência": quanto mais incerta a reação, maior sua hesitação, o que consequentemente amplia a distância entre o ser vivo e os objetos nos quais está interessado, independentemente das "promessas" ou "perigos" oferecidos por tais objetos. Evidencia-se assim, "a parte de independência de que um ser vivo dispõe", a "zona" de indeterminação que cerca sua atividade 5 . E essa relação estrita entre a "amplitude da percepção" e o grau de indeterminação da ação pode ser traduzida pela seguinte lei: "a percepção dispóe do espaço na exata proporçáo onde a ação dispóe do tempo”. Ora, qual o fundamento dessa relação constante?

Para explicá-lo, Bergson propõe uma simplificação das condições nas quais a percepção consciente se realiza (BERGSON, 1970, p. 183). Exclui "provisoriamente" da percepção toda contribuição da memória, tomando-a como uma percepçáo existente de direito e náo de fato, uma percepçáo que denomina pura, fundamento de nosso conhecimento: "[...] aquela que teria um ser situado onde estou, vivendo como vivo, mas absorvido no presente, e capaz, pela eliminação da memória [...], de obter da matéria uma visão ao mesmo tempo imediata e instantânea” (BERGSON, 1970, p. 185) ${ }^{6}$. Ora, uma imagem existe sendo solidária das outras imagens, continuando-se nas imagens que a seguem e prolongando aquelas que a precedem (BERGSON, 1970, p. 186). Age "[...] por cada um de seus pontos sobre cada um dos pontos das outras imagens", transmite "[...] a totalidade do que ela recebe", opõe "[...] a cada ação uma reação igual e contrária", não é senão "[...] um caminho sobre o qual passam em todos os sentidos as modificaçóes que se propagam na imensidão do universo" (BERGSON, 1970, p. 186). Enfim, “[...] pode

\footnotetext{
${ }^{5}$ Nos casos em que a percepção se assemelha a um "simples contato", a reação torna-se imediata e necessária, "[...] e o processo completo de percepçấo e reaçấo distingue-se dificilmente então do impulso mecânico seguido de um movimento necessário" (BERGSON, 1970, p.182).

${ }^{6}$ É a memória que nos faz crer que nossa representação é interior. "Eliminando-a”, Bergson pretende pensar a percepção em sua objetividade pura: de um lado, a indeterminaçáo do corpo vivo, de outro, a matéria. Nesse sentido, trata-se de uma percepção impessoal e provisória, pois não há jamais instantâneo para nós: "Por mais breve que se suponha uma percepção, com efeito, ela ocupa sempre uma certa duração, $e$ exige consequentemente um esforço de memória que prolonga uns nos outros uma pluralidade de momentos" (BERGSON, 1970, p. 184, grifos nossos). Assim, após colocar-se na hipótese de uma percepçáo pura e procurar entender como ela se explica, Bergson, como veremos, reintegra a memória na percepção, completando e "corrigindo" sua "exposição esquemática".
} 
ser sem ser percebida; pode estar presente sem ser representada” (BERGSON, 1970, p. 185). Qual seria, por conseguinte, o índice da diferença entre sua presença (o que ela é em si) e sua percepção (o que ela é para mim)?

Não seria o acréscimo de algo à imagem e sim a diminuição: a representação da imagem é menos que sua simples presença; como se o conjunto de imagens tivesse que renunciar à sua riqueza interna, dada pela totalidade de relaçôes recíprocas e necessárias das imagens que o constituem (PRADO JÚNIOR, 1989, p. 159). Também não seria a iluminação da imagem, mas seu obscurecimento por certos lados, a diminuição de sua maior parte. Converter a presença da imagem em representação é "[...] suprimir de uma só vez o que a segue, o que a precede, e também o que a preenche" (BERGSON, 1970, p. 186). A simples presença do organismo vivo causaria tal supressão, tal obscurecimento e tal diminuição de ser. Como salientamos, "a vida introduz a diferença”. Mais precisamente, a presença do ser vivo no universo das imagens introduz uma mudança na própria configuração dessas imagens: delas, o que se destaca são as partes pelas quais as funçôes desse organismo se interessam. Bergson compara nossa percepção das coisas a certos fenômenos de reflexão da luz que se originam de uma refração impedida: como um efeito de miragem (BERGSON, 1970, p. 187). Se, em sua totalidade, as imagens agem e reagem entre si, nenhuma se diferenciando da outra justamente porque estáo todas ao mesmo tempo apresentando todas as suas faces umas às outras, ao entrarem em contato "com uma certa espontaneidade de reaçáo", centro de atividade verdadeira, elas diminuem seu movimento de ação recíproca: os raios vindos da totalidade das imagens e que interessam a esta "atividade espontânea" "pareceram retornar" (não conseguem atravessá-la), delimitando os "contornos do objeto que os emite" . Nesse processo, dois pontos a ressaltar. Primeiramente, a diferença de grau (diminuição) apresentada pelas imagens entre ser e ser conscientemente percebidas, depois, o caráter seletivo de nossa percepção exterior, essencialmente escolha. Bergson resume esses dois pontos numa afirmação emblemática:

Num certo sentido, poderíamos dizer que a percepçáo de um ponto material inconsciente qualquer, em sua instantaneidade, é infinitamente mais vasta e

\footnotetext{
${ }^{7}$ BERGSON, 1970, p. 187. E ainda: "Quando um raio de luz passa de um meio a outro ele o atravessa geralmente mudando de direção. Mas tais podem ser as densidades respectivas dos dois meios que, para um certo ângulo de incidência não haja mais refração possível. Então se produz a reflexão total. Se forma do ponto luminoso uma imagem virtual que simboliza de certa maneira, a impossibilidade dos raios luminosos prosseguirem seu caminho. A percepçáo é um fenômeno do mesmo gênero" (Idem, ibid.).
} 
mais completa que a nossa, já que esse ponto recolhe e transmite as açóes de todos os pontos do mundo material, enquanto nossa consciência só atinge algumas partes por alguns lados. (BERGSON, 1970, p. 187).

Nossa percepção exterior, nesse sentido, é necessariamente pobre, uma vez que escolhe, seleciona as imagens em função de seus interesses. Por outro lado, com essa escolha, que no nível da percepção exterior é consciência ${ }^{8}$, surge algo de positivo que já anuncia o espírito: trata-se do "discernimento" (no sentido etimológico do termo); esse discernimento corporal é o que impede que "os centros de atividade espontânea" sejam atravessados pela totalidade das imagens - graças a ele a totalidade ao refletir-se, delimita-se, destacando-se como objeto. Do contrário - não havendo discernimento, perceberíamos "todas as influências de todos os pontos de todos os corpos", desceríamos "ao estado de objeto material". "Perceber conscientemente significa escolher, e a consciência consiste antes de tudo neste discernimento prático" (BERGSON, 1970, p. 198).

Dessa forma, em sua relação com os objetos, o corpo vivo introduz o discernimento como aquilo que modifica a forma ou o aspecto das imagens: selecionando-as, faz com que deixem de ser o que são em si $^{9}$ para serem algo para ele, em suma, se tornem objeto de sua ação e de suas necessidades ${ }^{10}$.

Para completar sua proposta, Bergson reintegra a memória na percepção. ${ }^{11} \mathrm{Ou}$ seja, como a percepção pura é uma percepção ideal, é preciso mostrar que nossa percepção concreta é na realidade um misto: as imagens passadas (lembranças) estão constantemente se misturando à percepção

\footnotetext{
8 "A consciência- no caso da percepção exterior- consiste precisamente nesta escolha" (BERGSON, 1970, p. 188).

9 "A realidade da matéria consiste na totalidade de seus elementos e de suas açóes de todo gênero" (BERGSON, 1970, p. 187).

${ }^{10}$ Essa conclusão possui um grande alcance teórico, pois, ao combater a tese de que o conteúdo da percepção nos seria interior (estaria no cérebro ou na consciência como conteúdos mentais), Bergson demonstra justamente que a única coisa que vem de nós, ou é relativa ao nosso corpo e à nossa ação, é a forma da imagem (percebida como um contorno); a representação do objeto e o próprio objeto são exteriores: na percepção não há qualquer processo interno de duplicação do objeto. Como afirma, no prefácio, a imagem tem como característica existir em si; e ainda, em O pensamento e o movente: "Não é em nós, é neles que percebemos os objetos; é pelo menos neles que nós os perceberíamos se nossa percepçáo fosse 'pura'” (BERGSON, 1970, p. 1317). Sobre o famoso exemplo do ponto $\mathrm{P}$, o qual permite a Bergson explorar o tema da exterioridade da percepção, são fundamentais as páginas 191 e 192 de Matéria e memória.

11 "É chegado o momento de reintegrar a memória à percepção, de corrigir assim o que nossas conclusóes podem ter de exagerado [...]” (idem, ibid., p. 213).
} 
presente, recobrindo-a e mesmo a substituindo, sendo a memória a responsável pelo aspecto subjetivo e individual de nossas percepçóes.

Enquanto recobre de uma camada de lembranças um fundo de percepção imediata, e enquanto também contrai uma multiplicidade de momentos, constitui a principal contribuição da consciência individual na percepção, o lado subjetivo de nosso conhecimento das coisas. (BERGSON, 1970, p. 184).

Ora, a atividade corporal, que significa antes de tudo "expectativa de ação possível", tem por base a duração da consciência, que é memória; por isso, nossas escolhas não se confundem com o puro capricho: sua indeterminação depende em grande parte da conservação das imagens percebidas. Elas nunca ocorrem ao acaso, mas se inspiram em experiências passadas, fazendo apelo aos rastros deixados pelas lembranças de situaçôes análogas. E nossas projeçóes para o futuro sempre se relacionam com uma "[...] perspectiva igual e correspondente sobre o passado” (BERGSON, 1970, p. 213). Nesse sentido, nossas percepçóes jamais são instantâneas, ou, por mais instantâneas que possam parecer, ocupam sempre uma determinada duração, há sempre nelas "um trabalho de nossa memória", de nossa consciência.

Bergson investiga o problema da memória e da relação entre percepção e lembrança, no segundo e terceiro capítulos do livro, os quais respectivamente tratam do reconhecimento das imagens e da sobrevivência das imagens. Para o que nos interessa, esse trabalho estudo trata da memória sob três formas: 1) como memória pura, a memória que registra todos os eventos de nossa vida pessoal sem negligenciar nenhum detalhe: cada fato, cada gesto, conservando assim, seu lugar e sua data (BERGSON, 1970, p. 227); 2) como memória hábito, a memória constituída pela repetição e reprodução automática dos mecanismos corporais; 3) e como memória imediata, a memória que faz a síntese entre as duas primeiras: contrai o passado puro na ação presente e inscreve os mecanismos corporais na representação. Bergson a ela se refere como "consciência imediata” ou concreta, que é ainda percepção e “já memória", e a define por um ato temporal (contração) que conserva os momentos do tempo, mas deles não retira o caráter sucessivo. Trata-se, por conseguinte, de uma memória coextensiva ao presente concreto e vivido pela consciência: "Na fração de segundo que dura a mais curta percepção possível de luz, trilhôes de vibraçôes surgiram, sendo que a primeira é separada da última por um intervalo enormemente dividido. Sua percepção, por mais instantânea que seja, consiste, portanto numa incalculável quantidade de 
elementos rememorados e, para falar a verdade, toda percepção é já memória” (BERGSON, 1970, p. 291). É essa memória imediata que estará em jogo, ao final da terceira parte de nosso texto.

3. O outro capítulo extremo de Matéria e memória propóe uma investigação que desemboca numa metafísica da matéria. Mais precisamente, é nesse quarto capítulo que se torna explícito, pela primeira vez, o método filosófico bergsoniano, o qual é anunciado e aplicado ao problema da matéria. Nesse sentido, e devido ao caráter eminentemente negativo da metafísica proposta por Bergson, sua investigação sobre a matéria procurará suplantar a visão da matéria elaborada no primeiro capítulo: como vimos, nesse capítulo, Bergson define a matéria, mas não tem como objetivo especular sobre sua essência; sua investigação insere-se no âmbito de uma teoria do conhecimento diferenciada, pois fundamentada na ação. Agora, tratar-se-á de justamente fazer a crítica a esse fundamento ou à fundação do conhecimento na ação. E consequentemente ultrapassar a ideia de matéria resultante do recorte imposto por nossa percepçáo ao universo material: ou seja, a ideia de matéria como um conjunto de imagens ou objetos isolados entre eles.

Como observamos no início deste texto, Bergson estende ao mundo material determinadas conclusōes do Ensaio. Tais conclusóes dizem respeito ao "trabalho utilitário do espírito", o qual, no âmbito da vida interior, consistia "[...] numa espécie de refração da duração pura através do espaço", responsável pela visão descontínua que tínhamos de nossos estados psicológicos, o que possibilitava nomeá-los, despersonalizá-los e inseri-los na vida social (BERGSON, 1970, p. 321). Aqui, em Matière et mémoire, o encontro do problema da união da alma e do corpo ${ }^{12}$ será o caminho para a consideração dos efeitos deste caráter utilitário também para o que nosso filósofo denominará, na sequência, "intuição exterior". O fio condutor dessa nova via encontra-se justamente no início do quarto capítulo do livro, momento em que resume suas análises dos capítulos anteriores por meio da seguinte conclusão: "[...] o corpo, sempre orientado para a ação, tem por funçâo essencial limitar, em vista da açâo, a vida do espirito” (BERGSON, 1970, p. 316 - grifo nosso). Porém, as questóes que possibilitaram essa conclusão "deixaram entrever [...], senão um meio de resolver o problema [da uniáo da alma com o corpo], pelo menos um lado por onde abordá-lo" (BERGSON, 1970, p. 317). E esse lado por onde abordá-lo

12 "Mas, por um lado, levantamos durante o caminho um problema metafísico que decidimos nẫo deixar em suspenso [...]” (BERGSON, 1970, p. 317). 
permite a formulação do "princípio geral do método" que, precisa Bergson, já foi utilizado "num trabalho anterior" ${ }^{\prime 3}$. A esse respeito, enfatiza inicialmente:

O que ordinariamente chamamos um fato, não é a realidade tal como aparece a uma intuiçáo imediata, mas uma adaptaçáo do real aos interesses da prática e às exigências da vida social. A intuiçáo pura, exterior ou interna, é a de uma continuidade indivisa. Nós a fracionamos em elementos justapostos, que respondem, aqui a palavras distintas, lá a objetos independentes. (BERGSON, 1970, p. 319).

Nossas necessidades de ordem prática e social assumem, portanto, um papel negativo importante, ao estarem na origem do rompimento da unidade de nosso conhecimento intuitivo; desfazer-se delas seria retomar contato com uma continuidade indivisa. Mas, se recortamos assim uma continuidade original, desejamos também, obcecados pela ideia de unidade, estabelecer uma unidade entre os termos já disjuntos, uma unidade que necessariamente será artificial. Bergson se refere ao "empirismo" e ao "dogmatismo" que, segundo ele, partem do real desse modo reconstituído ${ }^{14}$. Nesse sentido, as metafísicas acabam por tornar-se "construçôes" e, "igualmente verossímeis", refutam-se mutuamente; compreende-se, por conseguinte, o aparecimento de uma filosofia crítica que considera todo conhecimento relativo e o fundo das coisas inatingível; uma filosofia que reconhece a fragilidade das construçóes metafísicas, mas que, diante da fragilidade constatada, opta por renunciar a construir. A referência a Kant é aqui explícita e fundamental, uma vez que é preciso combater o argumento da relatividade e da impotência de nosso conhecimento especulativo: essa impotência reivindicada por Kant seria na verdade a de um conhecimento guiado pelas necessidades e sua satisfação; e a relatividade não estaria vinculada à "estrutura fundamental de nosso espírito", mas à forma contingente imposta por nossa estrutura de ser vivente e agente. Nosso conhecimento das coisas não seria, portanto, definitivamente relativo. Poderíamos ultrapassar essa relatividade, ou melhor, retornar a um contato primitivo, sensível ou imediato com o real. Como vemos, Bergson opóe dois gêneros de conhecimento: o mediato, de ordem prática, e o imediato

\footnotetext{
${ }^{13} \mathrm{Ou}$ seja, o Ensaio sobre os dados imediatos da consciência.

${ }^{14} \mathrm{O}$ "dogmatismo" estaria vinculado mais à forma, o "empirismo" à matéria. Estes últimos, embora conferindo um alto valor à experiência, teriam realizado uma reconstruçấo do real que segue "[...] as linhas interiores da estrutura das coisas"; os primeiros teriam aceitado e adotado a mesma reconstrução das coisas, porém, ao buscarem sintetizá-las sem uma "intuição", desembocam consequentemente numa síntese arbitrária.
} 
ou intuitivo, de ordem especulativa; este último nos proporcionaria um conhecimento da realidade das coisas e de nós mesmos, não mais uma ação sobre elas: seria propriamente um conhecimento metafísico. Tal o método ${ }^{15}$ proposto por Bergson.

Quanto à sua aplicabilidade ao problema da matéria, seria preciso saber se, "[...] nesta 'diversidade de fenômenos' da qual falou Kant, a massa confusa com tendência extensiva poderia ser apreendida aquém do espaço homogêneo sobre o qual ela se aplica", tal como nossa vida interior pode ser apreendida como duração pura, uma vez desvinculada do tempo homogêneo (BERGSON, 1970, p. 323). Colocar tal condição, explica nosso autor, não é negligenciar as "condiçôes fundamentais da percepção exterior"; a questão é somente saber se as condiçôes que tivemos sempre como fundamentais não são senão fundamentais para o uso ou a vantagem que desejamos obter das coisas, mais do que para o conhecimento puro que podemos ter delas. Pois trata-se de justamente "contestar" a solidariedade da extensáo concreta ao "espaço amorfo e inerte que a subtende", de modo que o "retorno ao imediato" seria, em consequência,, "[...] numa certa medida, libertar-se do espaço sem sair da extensão", isto é, Bergson pretende examinar a matéria de nosso conhecimento sem a intervenção da forma espacial: o que efetivamente percebemos é a "extensão"; o espaço não é senão um fruto de nossa concepção, um esquema (BERGSON, 1970, p. 323); em outras palavras, não é o espaço que define a exterioridade ${ }^{16}$.

Bergson apresenta os resultados da aplicação desse método ao problema da matéria, e que interessam ao seu propósito, sob a forma de quatro proposiçóes para ele, não está em questão construir uma "teoria da matéria”. Essas proposições, que constituem uma parte fundamental e decisiva do quarto capítulo, revelam em seu conjunto a construção progressiva de um argumento cujo objetivo é realizar a passagem da tese acerca da indivisibilidade do movimento à da

\footnotetext{
${ }^{15}$ A formulação mais geral desse método aparece em 1903, em Introdução à metafísica, texto no qual Bergson dá continuidade e prolonga algumas direçôes aqui apenas esboçadas.

${ }^{16}$ Como aponta Frédéric Worms, em Bergson, o problema do espaço envolve a "[...] relação entre nosso pensamento, do qual ele é a própria forma, e a realidade, da qual ele deforma a natureza temporal. Longe de constituir a essência da matéria (como em Descartes), ou de constituir uma estrutura de nossa intuição sensível (portanto de todo acesso aos fenômenos exteriores), o espaço é portanto em Bergson o resultado de um ato de concepçáo próprio a nosso espírito, indexado além disso sobre as necessidades de nossa ação ou de nossa espécie. Desde então, a própria matéria lhe escapa, seja inteiramente ( segundo Matéria e memória, que vê em seu fundo um grau de duração), seja em parte (segundo A evolução criadora, que nela vê um movimento de espacializaçáo, oposto ao movimento inverso da vida, mas jamais redutível ao espaço puro e vazio da geometria)" (WORMS, 2000, p. 24).
} 
continuidade da matéria ou, mais precisamente, da análise direta do movimento e das qualidades sensíveis "fora de nós" à metafísica da matéria. Tentemos, pois, compreender o que está em jogo nessa passagem, para nós crucial, na medida em que nos encaminha para a conclusão de nosso texto.

Bergson parte de uma proposição de cunho universal e formal, na qual afirma a indivisibilidade do movimento ${ }^{17}$, e apenas na segunda proposição procura mostrar sua realidade física: "Há movimentos reais" (BERGSON, 1970, p. 329). Isto é, há mudanças concretas ocorrendo no universo: “[...] o aspecto do universo material muda, a configuraçáo interior de todo sistema real varia, e não temos mais escolha aqui entre a mobilidade e o repouso" (BERGSON, 1970, p. 329). Ora, qual é o signo desta realidade do movimento, de sua concretude? Essencial, para nosso autor, é pensar o movimento como mudança qualitativa, mostrar que a qualidade é precisamente o que nele há de real. Nesse sentido, endereça uma crítica à filosofia moderna e suas soluçóes para o problema do movimento: referindo-se explicitamente a Descartes e a Newton, afirma que tanto a teoria da pura relatividade do movimento, defendida por Descartes ${ }^{18}$, quanto à teoria do espaço absoluto, sustentada por Newton e Euler, ignoram o aspecto qualitativo do movimento e por isso procuram fundar sua realidade sobre "uma causa" que dele se distingue. Ora, a realidade do movimento deve ser fundada nele mesmo, enquanto mudança: todo símbolo matemático que pretenda defini-lo apenas o transformará em relativo: "[...] não há símbolo matemático capaz de exprimir que é o móvel que se move e não os eixos ou os pontos aos quais o relacionamos" (BERGSON, 1970, p. 330). A certeza em relação à sua realidade me é revelada quando "[...] o produzo depois de ter desejado produzi-lo, e que o sentido muscular dele me traz a consciência. Ou seja, toco a realidade do movimento quando ele aparece a mim interiormente, como uma mudança de estado ou de qualidade". Contudo, não seria o mesmo em relação à percepção das "mudanças de qualidade nas coisas"? Como a percep̧̧âo da passagem de um som a outro ou ao silêncio?

O som difere absolutamente do silêncio, como também um som de outro som. Entre a luz e a obscuridade, entre cores, entre nuances a diferença é absoluta. A passagem de uma a outra é, ela também, um fenômeno real. Considero portanto as duas extremidades da cadeia, as sensaçóes musculares

\footnotetext{
17 "Todo movimento, enquanto passagem de um repouso a um repouso, é absolutamente indivisível" (BERGSON, 1970, p. 324).

${ }^{18}$ Em toda essa análise Descartes é o grande interlocutor de Bergson, pois, para ele, trata-se, sobretudo, de contestar a redução da matéria à extensão geométrica ou ao espaço.
} 
em mim, as qualidades sensíveis da matéria fora de mim, e tanto num caso como no outro eu não apreendo o movimento, se movimento há, como uma simples relação: é um absoluto. (BERGSON, 1970, p. 331-332).

Assim, são as qualidades sensíveis que conferem realidade ao movimento, ou melhor, o movimento é real como mudança, passagem de uma qualidade a outra qualidade - essa mudança que é essencial. Como afirma Bergson, trata-se de uma relação absoluta, muito diferente da mudança de um lugar a outro lugar, que a ele fosse permutável.

Essas consideraçóes conduzem nosso filósofo a uma abordagem da matéria como continuidade qualitativa e movente. Emblemática, nesse ponto, é a passagem que abre a terceira proposição, já de cunho metafísico: “Toda divisão da matéria em corpos independentes com contornos absolutamente determinados é uma divisão artificial”. Prossegue, ainda:

Um corpo, ou seja, um objeto material independente, se apresenta inicialmente a nós como um sistema de qualidades, onde a resistência e a cor - dados da visão e do tato - ocupam o centro e mantêm suspensas, num certo sentido, todas as outras. De outra parte, os dados da visão e do tato são os que se estendem mais manifestamente no espaço e o caráter essencial do espaço é a continuidade. (BERGSON, 1970, p. 332).

Nessa perspectiva, a síntese das qualidades apresentadas pelos objetos materiais independentes é artificial, como se fosse preciso destacar as qualidades desta síntese, para então reencontrar uma continuidade primitiva, própria às qualidades: no caso da visão, reencontraríamos a continuidade de um "campo visual"; no caso do tato, a continuidade de um percurso tátil feito sem "interrupção verdadeira". Bergson focaliza uma extensão material primitivamente percebida, que muda certamente de aspecto de um momento para outro, mas da qual não conseguimos perceber a mudança de conjunto, e apenas buscamos em sua mobilidade "pistas seguidas por corpos em movimento".

Uma continuidade movente nos é dada, onde tudo muda e permanece ao mesmo tempo: como se explica que dissociemos esses dois termos, permanência e mudança, para representar a permanência por corpos e a mudança por movimentos homogêneos no espaço? Este não é um dado da intuição imediata. (BERGSON, 1970, p. 333). 
Ora, nossos hábitos e as "necessidades da vida prática" estão na origem de toda descontinuidade introduzida na matéria. E essa maneira de "representar" a matéria é definida por Bergson como psicológica, haja vista que a psicologia tem como característica principal uma certa orientação prática de nossa representação (BERGSON, 1970, p. 168).

Abaixo dos princípios da especulação, táo cuidadosamente analisados pelos filósofos, há estas tendências das quais se negligenciou o estudo e que se explicam simplesmente pela necessidade que temos de viver, ou seja, em realidade, de agir. (BERGSON, 1970, p. 333).

Assim, se a vida introduz descontinuidade ${ }^{19}$ no mundo material sob o aspecto de "corpos com contornos definidos" no espaço e separados por intervalos vazios, é preciso ainda observar que Bergson pensa a vida como um princípio de ação. Dos hábitos contraídos na ação surgem "preconceitos" que consequentemente interferem em nossa especulaçáo, criando problemas factícios: o trabalho do metafísico, que visa especialmente a penetrar "o interior das coisas", será, em seu início, o de dissipar as obscuridades assim engendradas (BERGSON, 1970, p. 168).

Em toda essa análise da matéria, Bergson inspira-se numa tendência da ciência de sua época, o eletromagnetismo, mais precisamente, nas teorias dos físicos Thomson e Faraday. Nesse sentido, escreve: "[...] a materialidade do átomo se dissolve cada vez mais sob o olhar do físico" (BERGSON, 1970, p. 335) ${ }^{20}$. Mais precisamente, de um físico que especula sobre a realidade da matéria e a desmaterializa, concebendo-a como campos de força e de energia. "E, de fato, vemos força e matéria se reaproximar e juntar-se à medida que o físico aprofunda seus efeitos" (BERGSON, 1970, p. 336). E mesmo que fale de átomos ou considere o átomo em sua individualidade, "[...] a solidez e a inércia do átomo se dissolverão, seja em movimentos, seja em linhas de força, cuja solidariedade recíproca restabelecerá a continuidade universal"

\footnotetext{
19 "Seja qual for a natureza da matéria, podemos afirmar que a vida nela estabelecerá já uma primeira descontinuidade, expressando a dualidade da necessidade e daquilo que deve servir para satisfazê-la" (BERGSON, 1970, p. 334).

20 "Não temos nenhum motivo, por exemplo, para nos representarmos o átomo como sólido, em vez de líquido ou gasoso, nem para nos figurarmos a ação recíproca dos átomos através de choques mais do que de qualquer outra maneira. Por que pensamos num átomo sólido e por que em choques? Porque os sólidos, sendo os corpos sobre os quais temos manifestadamente mais influência, são os que nos interessam mais em nossas relaçóes com o mundo exterior, e porque o contato é o único meio do qual parecemos dispor para fazer agir nosso corpo sobre os outros corpos" (BERGSON, 1970, p. 335).
} 
(BERGSON, 1970, p. 336). Assim, a análise bergsoniana do movimento real encontra nessa física especulativa a confirmação de sua tese sobre a realidade da matéria, pois, à medida que essa ciência se aproxima do estudo dos últimos elementos da matéria, constata-se o desvanecimento da descontinuidade introduzida por nossa percepçáo. Dessa maneira, ela nos indica um modo de olhar a matéria, nos incita a nela ver "[...] modificaçóes, perturbaçôes, mudanças de tensão ou de energia, e nada mais". Essa direção da ciência vem juntar-se ao dado imediato revelado pela análise metafísica, que apresentava o movimento “[...] não como uma simples mudança de relação entre objetos aos quais ele se acrescentaria como um acidente, mas como uma realidade verdadeira e de certa maneira independente" (BERGSON, 1970, p. 337). Enfim, Bergson acredita que ciência e consciência estariam de acordo com sua quarta e última proposição: "O movimento real é antes o transporte de um estado do que de uma coisa” (BERGSON, 1970, p. 337).

Como destacávamos, Bergson pretende encontrar "[...] senão um meio de resolver o problema [da união da alma com o corpo], pelo menos um lado por onde abordá-lo" (BERGSON, 1970, p. 317). A nosso ver, esse lado por onde abordá-lo se define nessa quarta proposição e tem como ponto decisivo o momento em que nosso filósofo afirma: "Formulando essas quatro proposiçóes, na realidade estreitamos progressivamente o intervalo entre dois termos que opomos um ao outro, as qualidades ou sensaçóes, e os movimentos" (BERGSON, 1970, p. 337). Ora, como estreitar essa distância, à primeira vista "intransponível"? E aproximar sensaçôes qualitativas, essencialmente indivisíveis e heterogêneas e movimentos quantitativos, homogêneos e "sempre divisíveis"? Como encontrar algo em comum entre uma coisa que está na consciência - sensaçóes qualitativas - e outra que se movimenta independente de nós, no espaço?21 Para tanto, Bergson começa por atribuir ao movimento real e concreto a "própria qualidade", o que significa que, em si mesmo, ele apresenta uma certa vibração interior, um escandir próprio.

O movimento que a mecânica estuda é uma abstração ou um símbolo, uma medida comum, um denominador comum que permite comparar entre eles todos os movimentos reais; mas estes movimentos, considerados neles mesmos são indivisíveis que ocupam duração, supõem um antes e

\footnotetext{
${ }^{21}$ Partindo da irredutibilidade dessas diferenças, o "dualismo vulgar" acaba isolando dois mundos: de um lado, "movimentos no espaço" - movimentos que, mesmo se compondo entre si, não dariam outra coisa senão movimentos; de outro, nossa consciência que, por um "processo misterioso", traduz esses movimentos em sensaçôes que são projetadas no espaço, sensaçóes que por sua vez recobririam, "[...] nẫo se sabe como", os movimentos que elas traduzem (BERGSON, 1970, p. 337-338).
} 
um depois, e religam os momentos sucessivos do tempo por um fio de qualidade variável que deve ter alguma analogia com a continuidade de nossa própria consciência. (BERGSON, 1970, p. 338).

Essa atribuição da duração ao movimento material constitui um verdadeiro ponto de inflexão na filosofia bergsoniana, algo que definitivamente a reorienta. $\mathrm{O}$ estabelecimento de uma aproximaçáo entre o movimento real e a consciência ${ }^{22}$ culmina inevitavelmente numa comparação ou distinção entre dois diferentes ritmos de vibração. Bergson refere-se ao movimento real (fora de nós) como sendo uma sensação diluída e escandida num número "incalculável de momentos", deixando implícito que, entre essa "sensação diluída" e a sensação propriamente dita haveria uma diferença de concentração de momentos - a sensação apresentaria uma vibração mais concentrada, pois se repartiria num número menor de momentos. A questão de fundo, que ele aponta, diz respeito à relaçâo entre esses dois tipos de "vibração", que precisamente significa a contração da "sensação diluída" ("mudanças menos heterogêneas") em sensaçôes conscientes (mudanças mais heterogêneas). Nesse sentido, indaga:

Não podemos conceber, por exemplo, que a irredutibilidade de duas cores percebidas deve-se, sobretudo à estreita duração na qual se contraem trilhóes de vibraçóes que elas executam em um de nossos instantes? Se pudéssemos esticar esta duração, ou seja, vivê-la em um ritmo mais lento, não veríamos, à medida que este ritmo desacelerasse, as cores desbotarem e se estenderem em impressóes sucessivas, ainda coloridas, sem dúvida, mas cada vez mais próximas de se confundirem com abalos puros? (BERGSON, 1970, p. 338).

A irredutibilidade das cores que percebemos é assim relativa à contração que nossa consciência efetua sobre uma imensidáo de vibraçóes da matéria. Fora de nosso olhar, as qualidades sensíveis possuem uma determinada vibraçáo interior, mais relaxada e diluída, repartindo-se num número "incalculável de momentos"; sob o nosso olhar, ou, ao se tornarem representativas, essas qualidades se apresentam contraídas em nossa memória. Ora, essa contração

22 "O que prejudica ordinariamente a aproximaçấo, é o hábito adquirido de ligar o movimento a elementos, - átomos ou outros, - que interporiam sua solidez entre o próprio movimento e a qualidade na qual ele se contrai. Como nossa experiência cotidiana nos mostra corpos que se movem, nos parece que, para sustentar os movimentos elementares nos quais as qualidades se reconduzem, é necessário pelo menos corpúsculos. O movimento torna-se entâo, para nossa imaginação, apenas um acidente, uma série de posiçôes, uma mudança de relaçōes" (BERGSON, 1970, p. 338-339). 
subjetiva, sendo obra nossa, concerne a um ato de nossa duração e de nossa memória capaz de contrair numa intuição única (um ritmo de duração muito estreito) os momentos múltiplos da duração material, de modo que, contraídos, estes (os ritmos naturais das duraçôes) passam a vibrar de modo diferente. Tal diferença é justamente a diferença entre a duração da matéria e a nossa: do ponto de vista da matéria, não é senão a diferença entre ser e ser percebida. Dessa forma, uma vez que não criamos as qualidades sensíveis, apenas somos responsáveis, por meio de nossa memória e seu ritmo próprio de contração, por seu aspecto subjetivo.

Trata-se, como vemos, de uma diferença de ritmo de duraçâo ou, mais precisamente, de uma “[...] diferença de tensão interior” (BERGSON, 1970, p. 376). Essa noção de tensão é aqui a "noção mediadora", única capaz de "atenuar" a oposição entre quantidade e qualidade. Com ela, nosso filósofo sustenta a possibilidade de representar duraçóes com ritmos diferentes:

$\mathrm{Na}$ realidade, não há um ritmo único da duração; podemos imaginar ritmos bem diferentes, que, mais lentos ou mais rápidos, mediriam o grau de tensão ou de relaxamento das consciências, e, assim, fixariam seus lugares respectivos na série dos seres. (BERGSON, 1970, p. 342).

Assim, Bergson pensa uma pluralidade de duraçóes a partir de uma analogia metafísica com nossa memória: isso, por sua vez, permite vislumbrar uma ontologia geral e diversificada de acordo com os diferentes graus ou ritmos de duração, os quais indicam os graus de ser ou de tensáo próprios às coisas. Nesse sentido, a duração de nossa consciência surge como apenas uma duração - um ritmo singular de tensão ou contração. Profundamente diferente, por exemplo, desse "tempo geral" tratado pelo físico: enquanto este último "[...] é capaz de armazenar, num intervalo dado, uma quantidade de fenômenos táo grande quanto se queira” (BERGSON, 1970, p. 340) ${ }^{23}$, ela vive um ritmo bem determinado, sendo somente capaz de concentrar, num intervalo dado, um "número limitado de fenômenos conscientes" (BERGSON, 1970, p. 341) ${ }^{24}$. Essa limitação é uma limitação relativa à percepção humana.

\footnotetext{
23 "No espaço de um segundo, a luz vermelha, - aquela que possui o maior comprimento de onda e cujas vibraçốes são consequentemente as menos frequentes, - realiza 400 trilhôes de vibraçôes sucessivas" (BERGSON, 1970, p. 340).

24 "Assim esta sensação de luz vermelha experimentada por nós durante um segundo corresponde, em si, a uma sucessão de fenômenos que, desdobrados em nossa duração com a maior economia de tempo possível, ocuparia mais de 250 séculos de nossa história" (idem, ibid., p. 341).
} 
Perceber consiste portanto, em suma, em condensar períodos enormes de uma existência infinitamente diluída em alguns momentos mais diferenciados de uma vida mais intensa, e em resumir assim uma história muito longa. Perceber significa imobilizar. (BERGSON, 1970, p. 342).

Tudo ocorre como se apreendêssemos, no ato de percepção, certas existências cujos ritmos ultrapassam a ela própria ${ }^{25}$; todavia, se por um lado nossa percepção, num "momento único" de sua duração, concentra uma infinidade de momentos de uma existência mais diluída, por outro, a supressão desse "ritmo particular" de duração - condição de nossa ação sobre as coisas - revela simplesmente que a essência do mundo material subsiste, isto é, uma continuidade de vibraçóes mais distendidas persiste movendo-se ininterruptamente.

As análises de Bergson sobre o movimento "fora de nós" culminam, enfim, numa redefinição do mundo material; sua essência é definida agora em termos de duração, ou de sucessão, pois, se, como vimos, a divisibilidade da matéria é fruto de um trabalho artificial do espírito, "[...] a matéria extensa, considerada em seu conjunto, é como uma consciência onde tudo se equilibra, se compensa e se neutraliza" (BERGSON, 1970, p. 353). Em si mesma, ela é animada por "[...] uma tensão interna, palpitação, em seu seio, de uma duração quase adormecida" (PRADO JÚNIOR, 1989, p. 162). Não mais totalidade de imagens, ela adquire o estatuto de realidade temporal, em certo sentido consciente e análoga à nossa duração. Ora, essa metafísica da matéria proposta por Bergson, muito diferente da análise desenvolvida no primeiro capítulo do livro, desemboca numa concepção nova (não mais objetiva), também metafísica da percepçáo, a qual, ao invés de separar, une sujeito e objeto: se, no ato de perceber, apreendemos algo que ultrapassa a própria percepçáo, como observamos acima, o universo material, no entanto, não "[...] difere ou se distingue essencialmente da representação que dele temos" (BERGSON, 1970, p. 343). Por isso, não se trata de opor simplesmente espírito e matéria, mas, principalmente de reestabelecer um vínculo entre duas formas ou dois graus de realidade. Após esse percurso, certamente não estranharemos sua afirmação, em 1908 (BERGSON, 1972, p. 774), de que um dos objetivos de

25 “[...] pressentimos na natureza sucessôes muito mais rápidas do que a de nossos estados interiores. Como concebê-las, e qual é esta duração cuja capacidade ultrapassa toda imaginação? Não é a nossa certamente; mas não é mais esta duração impessoal e homogênea, a mesma para tudo e para todos, que se desenvolveria, indiferente vazia, fora daquilo que dura" (BERGSON, 1970, p. 342). 
seu terceiro livro, A evolução criadora, é a compreensão do universo material como sendo de mesma natureza que o eu.

MARQUES, Silene Torres. The search for the experience at its source: matter, movement and perception in Bergson. Trans/Form/Ação, Marília, v. 36, n. 1, p. 61-80, Jan./Abril, 2013.

\begin{abstract}
Our aim is to highlight some issues concerning the problem of matter and movement in the philosophy of Bergson. Issues presented in his second book, Matter and Memory, which indicate a new direction of his philosophy: the transition from psychology to metaphysics, more precisely, introducing the theme of movement and duration "outside of us." The first chapter of the book, in describing the material universe as a set of images plays a key role in this passage, which effectively occurs in the fourth chapter, at which time elaborates metaphysics of matter. Beyond this context, it is in the direction of his third book, Creative Evolution, that the metaphysics of matter will consequently point.
\end{abstract}

KEYWORDS: Bergson. Matter. Movement. Perception. Duration.

\title{
REFERÊNCIAS
}

BERGSON, Henri. Euvres. Édition du Centenaire, Textes annotés par André Robinet, Introduction de Henri Gouhier. Paris: PUF,1970.

. Mélanges. Textes publiés et annotés par André Robinet. Paris: PUF, 1972.

DELEUZE, Gilles. Le Bergsonisme. Paris: PUF, 1997.

DESCARTES, R. Méditations métaphysiques. Paris: Garnier-Flammarion, 1979.

PRADO JÚNIOR, Bento. Presença e Campo Transcendental - Consciência e Negatividade na Filosofia de Bergson. São Paulo: EDUSP, 1989.

WORMS, Frédéric. Le vocabulaire de Bergson. Paris: Ellipses, 2000.

Bergson ou les deux sens de la vie. Paris: PUF, 2004.

Recebido em: 23.08.2012

Aceito em: 24.09 .2012 